In fact, the symptoms were so prominent as to put it beyond all doubts that the disease was scarlatina. Of course all the cases were isolated, and every precaution used to prevent its spread. Soon after the draft arrived, two or three men of it were admitted with what was then put down as a feverish attack. I am now inclined to think they were suffering from that very mild form of scarlatina which often escapes detection. Indeed, one of the men was, shortly after discharge, re-admitted suffering from anasarca.

In the treatment the warm bath was freely used, and gave very great relief to most of the cases.

The draft landed at Bombay on the 1st of February, 1871. July 20 th, 1871 .

\section{A CASE OF MONSTROSITY.}

\section{By James Cleghorn, M.D., Civil Surgeon, Jounpore.}

A REPORT reached me last month, that a child had been born, in a village fifteen miles from this, with four legs and three sets of genital organs. The information was received from such a reliable source, that $I$ had no doubt a monster of some kind had been born, and to satisfy myself as to its nature, I visited the village on the 27 th May, and found the report to be in a great measure quite correct. In answer to my enquiries, a fully-grown, fairly-developed and vigorous male child was produced, that had attached to the lower part of its epigastric region, towards the right, a pair of legs and a pelvis, that in appearance might have belonged to a fotus of the sixth or seventh month. The toes and feet were well formed, the knees semi-flexed and anchylosed, the hip-joints moveable, and the legs abducted, and placed one on each side of the parent child. The sacrum and brim of the pelvis were directed upwards and backwards, in relation to the child, and the pedicle of attachment, which was short, was formed by a continu. ation of the skin from the brim of the upper outlet, so that if the pedicle was cut across, the interior of the pelvis would be exposed. A portion of umbilical cord, one inch in length, with its free end smooth, bulbous and without cicatricial marks, was attached to the upper surface of the pedicle, rather to the left; and underneath, attached to the pubic region, hung a well-formed penis and scrotum. The testicles were absent. The anus was imperforate, but a tubercle marked its position.

The skin covering these supernumerary parts was in all respects similar to that on the body of the child.

A tumour, the size of a small orange, projected from the umbilical region of the child. The father informed me that the umbilical cord had sprung from the centre of this, and that during the separation of the remains of the navel string, the swelling had increased in size, and burst at one point, giving escape to a watery fluid; it had been covered with cow dung, so that the position of the navel could not be ascertained.

While making my examination the child urinated, and in about half a minute afterwards a small quantity of urine was also passed through the penis of the supernumerary parts.

The father stated that the child had been born sixteen days ago, and that it sucked well, and had regular motions, but was peevish and frequently crying. He also said that the mother had carried it for ten months, that she was in labour half a night, and that there did not appear to be any difficulty in delivery. There was only one placenta. None of his other children, two in number, were in any way deformed.

The child died on the 6th June, having lived for twenty-six days. The body, although placed in country spirits shortly after death, showed signs of decomposition when I received it next day. The body, without the brain, weighed $6 \mathrm{lbs} .2$ ozs. and measured $19 \frac{1}{2}$ inches in length. The supernumerary parts measured, from the iliac crest to the heel, following the curve of the knee, $6 \frac{3}{4}$ inches. The feet were $2 \frac{3}{8}$ inches long.

I opened the abdomen and chest on the left side, so that a flap could be reflected, and the internal organs examined, without interfering with the integrity of the specimen. There were two distinct peritoneal cavities; that of the child contained a liver so greatly enlarged, that it appeared to consist of two separate organs, that had become amalgamated, but I could only discover one gall bladder. Its right lobe, which was most enlarged, was directed downwards, and formed the umbilical tumour. It was intimately adherent to the abdominal wall. The kidneys were large and lobulated; the right was displaced towards the middle line. The spleen was normal. The bowels were perfect in all their parts, but were soft and discoloured. The lungs were imperfectly expanded and congested. The heart appeared normal, but its texture was so very soft, that it was impossible to make an exact examination. The aorta divided into three equal branches in the lumbar region, two of which passed over to supply the supernumerary parts. Decomposition having commenced in the internal organs, they were all removed.

The second peritoneal cavity was situated underneath the right side of the diaphragm, and contained a few inches of small intestine, and a globular-shaped, slightly-lobulated kidney, the size of a marble. The portion of intestine contained meconium, and was attached to the posterior wall by a broad fold of mesentery. The kidney was contained between the folds of the mesentery, and two ureters passed down between the layers, to the pelvis of the supernumerary parts.

I have not examined the parts minutely, as to do so would necessitate the destruction of the specimen. What has been described is, I think, sufficient for all practical purposes, and shows that these supernumerary parts were not produced by the "fusion of germs," but, as Carpenter says, from a "single germ, which, being possessed of an unusual formative capacity, has evolved itself into a structure containing more than the usual number of parts, and comparable to that which may be artificially produced by partial tission of the bodies of many of the lower animals," or it may be an instance of developement by gemmation after the Ascidian type; a reversion to our early progenitor, which, according to Darwin, seems to have been more like the larvæ of our existing marine Ascidians, than any other known form.

The absence of the brain and spinal cord, and a separate circulatory system, shows, I think, that the additional parts did not spring from a separate ovum, but were merely a budding from the one which produced the child; as in the case of the additional thumbs so frequently seen in India.

\section{NOTES ON A CASE OF LEUCODERMA.}

By Assistant Surgeon A. Wood, M.D.

REadivg somewhere, a short time ago, an article on the diagnosis between white leprosy and leucoderma, which then greatly interested me, I was soon afterwards gratified by having to treat a case of the latter, so well marked, as perhaps to justify my offering a few remarks thereon, in the hope that they may prove as acceptable to others, as the actual observation of the case was to myself.

The affection was exhibited in the person of a recruit in the regiment, a Pathan, young, strong and well proportioned, with no signs of any other disease, past or present; no history of syphilis could be made out, which with 'baras' or white leprosy and this same disease is, among natives, at least, so often confounded. There was no tendency to scrofula in the patient's constitution. No unwonted exposure had been undergone. 'No unusual nor uncommon food had been indulged in, and no contagion had been run the risk of. In fact, no cause what- 